\title{
EFFECTS OF AROCLOR 1254 ON THE DNA METHYLATION OF IMPRINTED GENES IN THE ADULT MOUSE SPERM
}

\author{
WANG, C. Y. ${ }^{1}-$ CUI, J. T. ${ }^{1}-$ LU, Z. L. ${ }^{1}-$ MA, X. L. ${ }^{1}-$ WANG, J. H. ${ }^{1}-$ SUN, Y. C. ${ }^{2 *}$ \\ ${ }^{I}$ College of Resources and Environmental Science, Jilin Agricultural University \\ Changchun 130118, PR China \\ (phone: +86-0431-84532955; fax: +86-0431-84532955) \\ ${ }^{2}$ Institute of Military Veterinary Medicine, Academy of Military Medical Sciences \\ Changchun 130122, PR China \\ *Corresponding author \\ e-mail: wangchengyu2001@163.com \\ phone: +86-0431-86985952; fax: +86-0431-86985952 \\ (Received 28 $8^{\text {th }}$ Oct 2016; accepted $28^{\text {th }}$ Feb 2017)
}

\begin{abstract}
As estrogen-like and anti-androgenic endocrine-disrupting chemicals, polychlorinated biphenyls have been reported to affect the male reproductive axis resulting in infertility. In the present study, Aroclor 1254 was administered to adult male mice, and its possible effects on the differentially methylated regions of two paternally (H19 and Gt12) and three maternally (Mest, Snrpn and Igf2r) imprinted genes were tested in the sperm DNA. In the control, the percentages of methylated CpGs were close to $100 \%$ and $0 \%$ in paternally or maternally imprinted genes respectively. Aroclor 1254 significantly decreased the percentages of methylated CpGs of H19 and Gt12 and markedly increased those of Mest, Snrpn, and Igf2r. In addition, dramatically increased mRNA expression of estrogen receptor $\alpha$ and $\beta$ were obtained in the treatment. We postulate that the effects of PCBs on male spermatogenesis and fertility rates might involve imprinting alterations in the sperm.
\end{abstract}

Keywords: polychlorinated biphenyls; endocrine disrupting chemicals; epigenetics; $C p G$ island; sperm cell

\section{Introduction}

Genomic imprinting is an epigenetic mechanism through which a subset of mammalian genes is expressed in a parental allele-specific manner. The parental-specific expression of genes is regulated by parent-specific epigenetic markers such as DNA methylation in the differentially methylated region (DMR) or imprinting control region (ICR) (Paoloni-Giacobino and Chaillet, 2006). These markers are independently established during gametogenesis (Morison et al., 2001). After fertilization in mice, the paternal genome undergoes active demethylation and the maternal genome undergoes passive demethylation, without affecting imprinting marks (Hammoud et al., 2010). Thus, the DNA methylation differences between maternal and paternal alleles of many imprinted genes are inherited from the male and female gametes and subsequently maintained during development (Surani et al., 1986; Lucifero et al., 2002). It is also reversible in that the methylation imprints are switched in the germ line to reflect the sex of the parent ( $\mathrm{Li}$ et al., 1993). Evidence of sex-specific 
differences in imprint acquisition suggests that male and female germ cells may be susceptible to perturbations in imprinted genes at specific prenatal and postnatal stages (Lucifero et al., 2004). Germ cells are a unique cell type that can transmit genetic information to the next generation. Germ cell development and early embryogenesis are crucial windows in the erasure, acquisition and maintenance of genomic imprints (Lucifero et al., 2002). Moreover, imprinted genes have been shown to play a key role in the regulation of embryonic growth and placental function during development (Strogantsev and Ferguson-Smith, 2012). The paternal-derived imprints are biased toward development of extra embryonic lineages, thereby promoting embryo growth (McGrath and Solter, 1984). The disruption of imprinting of genes in spermatogenesis commonly result in infertility and developmental problems (Hammoud et al., 2010; Hitchins and Moore, 2004).

Polychlorinated biphenyls (PCBs) are a group of halogenated aromatic hydrocarbons, synthetic chemicals which do not occur naturally in the environment. They belong to a group of widespread environmental pollutants, and their ecotoxicological impact on living organisms was of great interest (Safe, 1994). The manufacture of PCBs was stopped and restricted in many countries since the 1970s. However, they continue to be detected as major global pollutants in the environment and biological samples and cause harmful health effects (Rudel and Perovich, 2009). Although PCBs are not necessarily fatal to wildlife and human, they are biomagnified along food chains, increasing a risk of human exposure due to their ubiquitous, persistent and lipophilic characters (Zhou and Zhang, 2005). PCBs are considered potential endocrine disruptors. They are estrogen-like and anti-androgenic chemicals in the environment contain potentially hazardous effects on male reproductive axis resulting in infertility and other hormonal dependent reproductive functions (Pflieger-Bruss and Schill, 2000; Fielden et al., 2001).

Evidence in animal models suggests that endocrine disruptors may affect not only the exposed individual but also the offspring and subsequent generations (Schug et al., 2011). The mechanism of transmission involves non-genomic modifications of the germ line such as changes in DNA methylation and histone acetylation. Several studies have shown an alteration in DNA methylation in the male germ cells on exposure to endocrine disruptors. Anway et al have revealed an association between altered methylation patterns in testicular germ cells and reduced male fertility in rats on exposure to endocrine disruptors, methoxychlor, and vinclozolin (Anway et al., 2005). Recent study has shown that in utero exposure of male rats with an antiandrogenic compound, vinclozolin, results in epigenetic transgenerational disease phenotype involving alterations in DNA methylation patterns at various loci in the spermatozoa (Chang et al., 2006). Reduced DNA methylation at imprinted loci in rat spermatozoa upon tamoxifen treatment indicated a role of estrogen-associated signaling in the acquisition of paternal-specific imprints during spermatogenesis (Pathak et al., 2009). In addition, association between DNA methylation and postimplantation loss suggests that errors in paternal imprints at imprinted loci could affect embryo development (Pathak et al., 2009). These experiments indicate that normal methylation patterns of imprinted 
genes in the male germ line are crucial for normal spermatogenesis and embryogenesis. The establishment of DNA methylation imprints in the male germ cells in adulthood and the possible influence of endocrine disruptors on male germ cell methylation suggest that exogenous epigenetic insults could be transmitted to the progeny, thereby affecting its developmental potential.

Aroclor 1254 is a pool of more than 60 congeners used for in vitro studies because its composition is representative of PCBs environmental pollution. Previous studies revealed the adverse in vivo effects of Aroclor 1254 on testicular germ cell development and spermatogenesis (Mi and Zhang, 2005), as well as the in vitro toxic and estrogenic actions of Aroclor 1254 on ovarian germ cell (Xie and Zhang, 2004). The above results indicated that Aroclor 1254 exposure imposed both toxic and hormonal effects on embryonic testicular germ cell proliferation, which may cause reproductive disorder and even infertility at adulthood. However, the effects of PCBs on DNA methylation patterns of imprinted genes in the male germ cells remain unknown. In the present study, five imprinted genes, H19, Gt12, Mest, Snrpn and Igf2r were chosen, and the effects of PCBs on DNA methylation patterns of sperm cells were evaluated at their DMR or ICR loci using bisulphate modification and cloning analysis.

\section{Methods}

\section{Animals and treatment}

Animals were cared for humanely according to the guidelines for animal experiments of the Academy of Military Medical Sciences. Male Kunming strain mice (age, 8 wk) were obtained from Biological Product Institute (Changchun, China). The mice were housed in standard polypropylene cages in a temperature-controlled room $\left(22^{\circ} \mathrm{C}\right)$ with a 12:12-h light-dark cycle. Commercial mouse pellets and water were provided ad libitum. The study was approved by the Institutional Animal Ethics Committee.

Adult male mice were administered $50 \mu \mathrm{g} / \mathrm{kg}$ body weight/day of Aroclor 1254 (Sigma Chemicals, Shanghai, China), by intraperitoneal injection, 5 days a week for 60 days (Mi and Zhang, 2005; Zhang et al., 2012). The chemical was suspended uniformly in arachis oil by sonication. Controls received arachis oil alone.

\section{Male mouse sperm cells collection}

The treated and control males were killed, and the vas deferens and cauda epididymis were dissected out, placed into a Petri dish, scored with a razor blade in a droplet of Phosphate Buffer Saline (PBS) and left at $37^{\circ} \mathrm{C}$ for $30 \mathrm{~min}$ to allow motile sperm to move into the medium. The latter was then transferred into a microcentrifuge tube and the tissue fragments were allowed to sediment during $30 \mathrm{~min}$ at $37^{\circ} \mathrm{C}$. The motile sperm remained in the supernatant, which was carefully transferred to another tube, and this procedure was repeated 3 times. The final supernatant was carefully removed and centrifuged at $6000 \times \mathrm{g}$ for $10 \mathrm{~min}$ to pellet the sperm. 


\section{DNA isolation and bisulfite sequencing}

Genomic DNA was extracted from male mouse sperm cells using EasyPure Genomic DNA Kit (Tiangen, Beijing, China) according to the manufacturer's instructions. The isolated DNA was treated with sodium bisulfite from an EpiTect Bisulfite Kit (Qiagen, Hilden, Germany) as per the manufacturer's instructions. Subsequently, the modified DNA sample immediately used in BS-PCR amplification or stored at $-20^{\circ} \mathrm{C}$. Three separate bisulfite modification treatments were performed for each DNA sample.

The bisulfite converted DNA was amplified by nested PCR for Igf2-H19 ICR, Dlk1-Gt12 IG-DMRIII, Mest promoter and exon1, Snrpn DMR1 and Igf2r DMR2 with primers. Specific primers for BS-PCR amplification were designed using Methyl Primer Express ${ }^{\circledR}$ Software v1.0 (Applied Biosystems, Foster City, CA, USA) and listed in table (Table 1). To generate the product for each imprinted gene, two rounds of PCR were done with fully nested primer pairs. The outside primer pairs were used for the first-round PCR, whereas the inside primer pairs were used for the second-round PCR.

Table 1. Primers for bisulfite PCR

\begin{tabular}{|c|c|c|c|c|}
\hline Gene & Primer set (5' to 3') & $\begin{array}{l}\text { Product } \\
\text { size(bp) }\end{array}$ & $\mathbf{T}_{\mathrm{a} 1} / \mathbf{T}_{\mathrm{a} 2}\left({ }^{\circ} \mathbf{C}\right)$ & $\begin{array}{c}\text { GenBank } \\
\text { accession no. }\end{array}$ \\
\hline $\begin{array}{l}\text { Igf2-H19 } \\
\text { ICR }\end{array}$ & $\begin{array}{l}\text { Outside forward: TTTTGGTTATTGAATTTTAAAAATTAG } \\
\text { Inside forward: GTGGTTTATTATAGGAAGGTATAGAAGT } \\
\text { Inside reverse: ACCTAAAATACTCAAACTTTATCACAAC } \\
\text { Outside reverse: ACCATTCCCTAAAATATCACAAATACC }\end{array}$ & 608 & $53 / 55$ & U19619 \\
\hline $\begin{array}{l}\text { Dlk1-Gt12 } \\
\text { IG-DMR } \\
\text { III }\end{array}$ & $\begin{array}{l}\text { Outside forward: GTATTGTAATATAGGTTAGGTG } \\
\text { Inside forward: GTATTGTAATATAGGTTAGGTG } \\
\text { Inside reverse: CACAACTACACAAAATACTAC } \\
\text { Outside reverse: CTACATAATACCATATAAACATATCTC }\end{array}$ & 499 & $53 / 52$ & AB291769 \\
\hline $\begin{array}{l}\text { Mest } \\
\text { promoter } \\
\text { and exon1 }\end{array}$ & $\begin{array}{l}\text { Outside forward: GATTTGGGATATAAAAGGTTAATGAG } \\
\text { Inside forward: TTTTAGATTTTGAGGGTTTTAGGTTG } \\
\text { Inside reverse: AATCCCTTAAAAATCATCTTTCACAC } \\
\text { Outside reverse: TCATTAAAAACACAAACCTCCTTTAC }\end{array}$ & 563 & $53 / 53$ & AF017994 \\
\hline $\begin{array}{l}\text { Snrpn } \\
\text { DMR1 }\end{array}$ & $\begin{array}{l}\text { Outside forward: TGTAATATGATATAGTTTAGAAATTAG } \\
\text { Inside forward: AATTTGTGTGATGTTTGTAATTATTTGG } \\
\text { Inside reverse: ATAAAATACACTTTCACTACTAAAATCC } \\
\text { Outside reverse: ATAAACCCAAATCTAAAATATTTTAATC }\end{array}$ & 420 & $52 / 54$ & AF063659 \\
\hline $\begin{array}{l}\text { Igf2r } \\
\text { DMR2 }\end{array}$ & $\begin{array}{l}\text { Outside forward: TTAGTGGGGTATTTTTATTTGTATGG } \\
\text { Inside forward: GTGTGGTATTTTTATGTATAGTTAGG } \\
\text { Inside reverse: AAATATCCTAAAAATACAAACTACAC } \\
\text { Outside reverse: AAATATCCTAAAAATACAAACTACAC }\end{array}$ & 206 & $52 / 53$ & L06446 \\
\hline
\end{tabular}

$\mathrm{Ta} 1 / \mathrm{Ta} 2$ represents the annealing temperatures for the 1 st and 2nd PCR, respectively. 
Each $50 \mu \mathrm{L}$ PCR reaction contained $2 \mu \mathrm{L}$ bisulfite-treated DNA, $5 \mu \mathrm{L} 10 \times \mathrm{PCR}$ buffer, 4 $\mu \mathrm{L}$ (2.5 mM each) dNTPs (Takara, Dalian, China), $2 \mu \mathrm{L}$ of both forward and reverse primers, $34.5 \mu \mathrm{L} \mathrm{dH} \mathrm{H}_{2} \mathrm{O}$, and $0.5 \mu \mathrm{L}$ Hot start DNA Taq Polymerase (Tiangen, Beijing, China).

Thermal cycling was carried out with a 5 min denaturation step at $94^{\circ} \mathrm{C}$, followed by 30 three-step cycles $\left(30 \mathrm{~s}\right.$ at $94^{\circ} \mathrm{C}, 30 \mathrm{~s}$ at different annealing temperatures listed in Table 1, and $30 \mathrm{~s}$ at $72^{\circ} \mathrm{C}$ ), and final extension at $72^{\circ} \mathrm{C}$ for $10 \mathrm{~min}$. For the second round of PCR, $1 \mu \mathrm{L}$ of the first-round sample was used and the conditions for the PCR were the same as above.

The PCR products were resolved on $1.2 \%$ agarose gels to confirm the specific amplification of the products by size, and then gel purified using the TIANgel Midi Purification Kit (Tiangen, Beijing, China). Purified products were cloned into pMD18-T vectors (Takara, Dalian, China) and plated onto AMP-X-GAL plates for blue-white screening. Positive colonies were reinoculated and then sequenced (Shenggong, Shanghai, China). Ten clones were analyzed for each sample for each imprinted gene.

\section{RNA extraction and quantitative PCR}

Total RNA was extracted by an EasyPure ${ }^{\mathrm{TM}}$ RNA Kit (TransGen, Beijing, China), and cDNA was synthesized by a TransScript ${ }^{\mathrm{TM}}$ First-Strand cDNA Synthesis SuperMix Kit (TransGen, Beijing, China).

The expression level of estrogen receptors (ER $\alpha$ and $E R \beta)$ were quantified on a StepOnePlus ${ }^{\mathrm{TM}}$ Real-Time PCR System (Applied Biosystems, Foster City, CA, USA) using TransStart ${ }^{\mathrm{TM}}$ Green qPCR SuperMix (TransGen, Beijing, China). The primers for quantitative PCR were designed using Primer Express ${ }^{\circledR}$ Software v3.0 for Real-Time PCR (Applied Biosystems, Foster City, CA, USA) and listed in table (Table 2).

Table 2. Primers for quantitative real-time PCR

\begin{tabular}{|c|c|c|c|c|}
\hline Gene & Primer set ( $5^{\prime}$ to $\left.3^{\prime}\right)$ & $\begin{array}{l}\text { Product } \\
\text { size(bp) }\end{array}$ & $\mathrm{T}_{\mathrm{a}}\left({ }^{\circ} \mathrm{C}\right)$ & $\begin{array}{c}\text { GenBank } \\
\text { accession no. }\end{array}$ \\
\hline $\mathrm{ER} \alpha$ & $\begin{array}{l}\text { Forward: AGGCATGGTGGAGATCTTTGA } \\
\text { Reverse: AATGATGGATTTGAGGCACACA }\end{array}$ & 100 & 60 & BC167246 \\
\hline $\mathrm{ER} \beta$ & $\begin{array}{l}\text { Forward:CAAGTCCGCCTCTTGGAAAG } \\
\text { Reverse:GGTCTGGAGCAAAGATGAGCTT }\end{array}$ & 100 & 60 & BC141075 \\
\hline$\beta$-actin & $\begin{array}{l}\text { Forward: TCTGGCACCACACCTTCTACAA } \\
\text { Reverse: TTTTCACGGTTGGCCTTAGG }\end{array}$ & 100 & 60 & BC138611 \\
\hline
\end{tabular}

Ta represents the annealing temperature for the quantitative real-time PCR.

Reaction mixture $(25 \mu \mathrm{L})$ contained $2 \mu \mathrm{L}$ cDNA template, $12.5 \mu \mathrm{L}$ TransStartTM Green qPCR SuperMix $(2 \times), 0.5 \mu \mathrm{L}$ of both PCR forward and reverse primers $(10 \mu \mathrm{M})$, $0.5 \mu \mathrm{L}$ Passive Reference Dye $(50 \times)$, and $9 \mu \mathrm{L}$ dH2O. Thermal cycling conditions were $95^{\circ} \mathrm{C}$ for $1 \mathrm{~min}$, followed by $40 \mathrm{PCR}$ cycles of $5 \mathrm{~s}$ at $95^{\circ} \mathrm{C}$ for DNA denaturation, and 30 $\mathrm{s}$ at $60^{\circ} \mathrm{C}$ for primer annealing and extension. The melting protocol was $65^{\circ} \mathrm{C}$ to $95^{\circ} \mathrm{C}$ (in increments of $\left.0.5^{\circ} \mathrm{C} / 5 \mathrm{~s}\right)$. Transcript of ERs were quantified in three replicates and 
calculated relative to the transcription in sample of the housekeeping gene, $\beta$-actin (endogenous control).

\section{Statistical analysis}

Every independent experiment was duplicated at least three times, and the data were presented as mean \pm SD. Significances were evaluated by a Student's t-test and set at $P<$ 0.05 .

\section{Results}

Methylation status and levels in the differentially methylated regions of the imprinted genes

The DNA methylation status and levels of H19 ICR, Dlk1-Gt12 IG-DMRIII, Mest promoter and exon1, Snrpn DMR1 and Igf2r DMR2 in the mouse sperm cells were analysed by bisulfite PCR (BSP). Methylation data from BSP sequencing were analysed by computing the percentage of methylated CpGs of the total number of CpGs.

The modifications of each imprinted gene methylation status were found to be evenly distributed between the CpGs (Figs.1, 2), with no particular one being more affected than the others. Therefore, no specific $\mathrm{CpG}$ sites were found to be more or less sensitive to Aroclor 1254 than the overall sites within the region studied.

H19

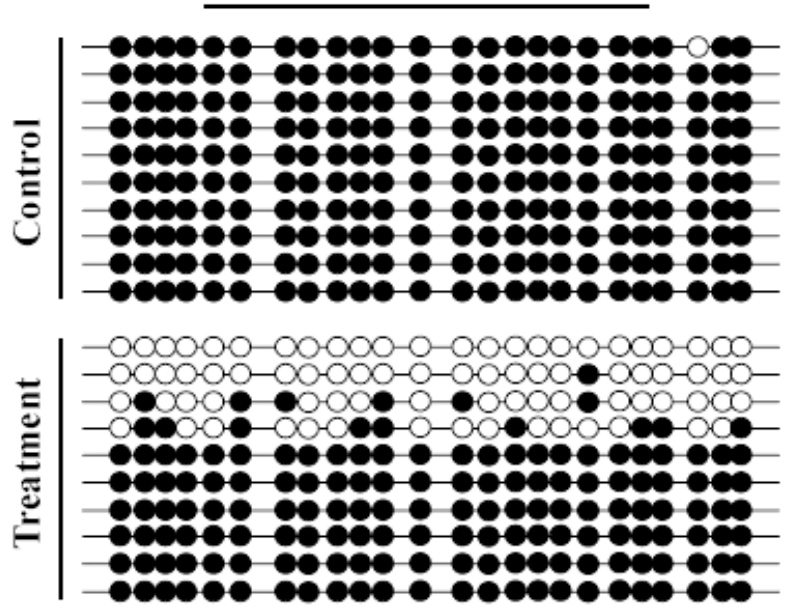

Gt12

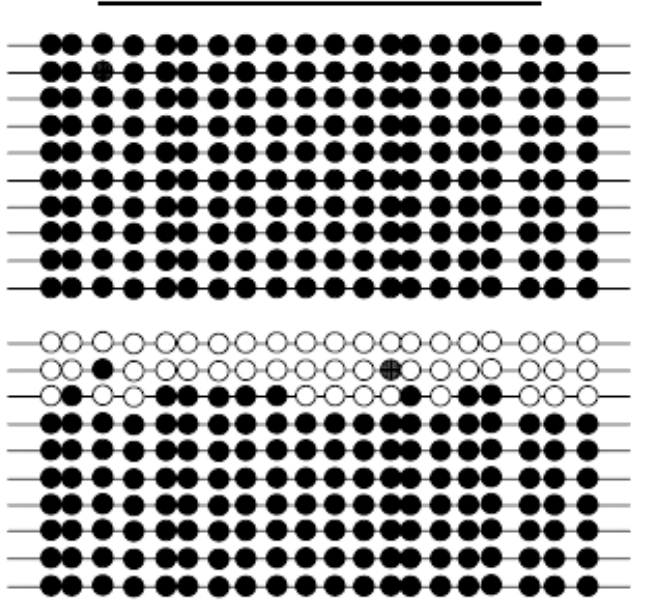

Figure 1. DNA methylation status of Igf2-H19 ICR and Dlk1-Gtl2 IG-DMRIII in the sperm cells of the control and Aroclor 1254-treated mice analyzed by BSP. Each line represents a single sequenced clone. Filled circles correspond to methylated cytosines and open circles represent unmethylated cytosines 


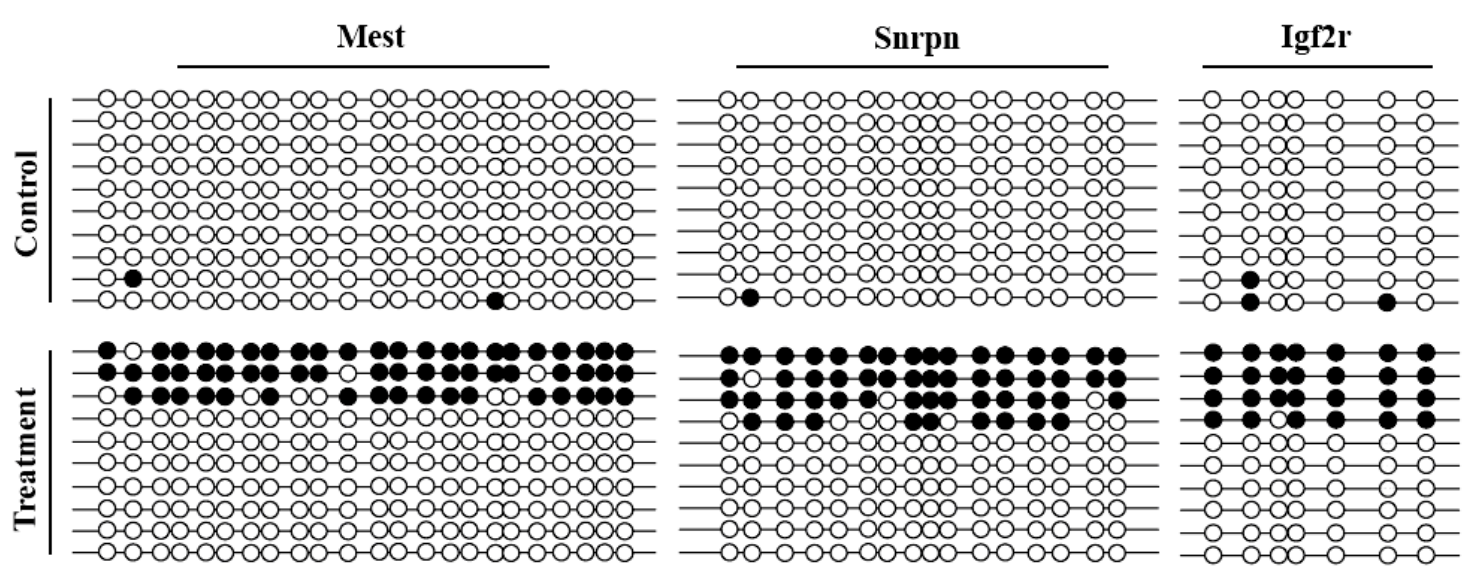

Figure 2. DNA methylation status of Mest promoter and exon1, Snrpn DMRI and Igf2r DMR2 in the sperm cells of the control and Aroclor 1254-treated mice analyzed by BSP. Each line represents a single sequenced clone. Filled circles correspond to methylated cytosines and open circles represent unmethylated cytosines

In the sperm of controls, the percentages of methylated $\mathrm{CpG}$ sites were close to the values of $100 \%$ and $0 \%$ of the total CpGs in paternally or maternally imprinted genes respectively (Figs. 3, 4). Aroclor 1254 induced dramatic changes of DNA methylation of imprinted genes in the sperm of treated male mice. The number of methylated CpGs of H19 and Gt12 were decreased (respective mean values $67.33 \%$ and $76 \%$ ), and those of Mest, Snrpn, and Igf2r increased (respective mean values $26.09 \%, 33.96 \%$, and $38.57 \%$ ). The Aroclor 1254 effects were all highly significant $(P<0.01$; Figs. 3, 4).

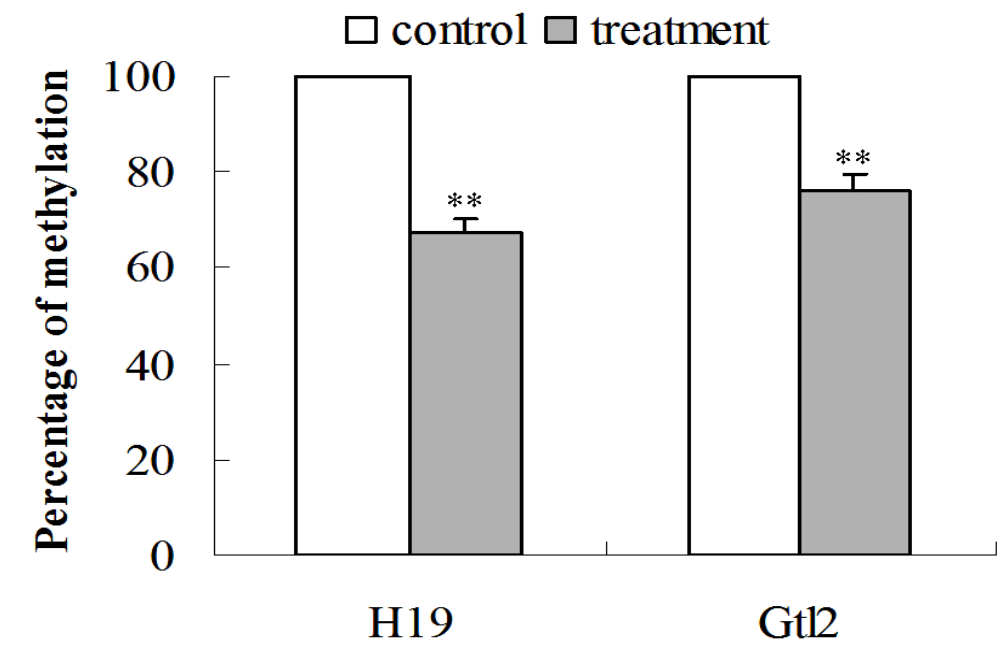

Figure 3. DNA methylation levels of Igf2-H19 ICR and Dlk1-Gtl2 IG-DMRIII in the sperm cells of the control and Aroclor 1254-treated mice analyzed by BSP. Statistically significant differences to the control are presented ( “**” for $P<0.01$ ) 


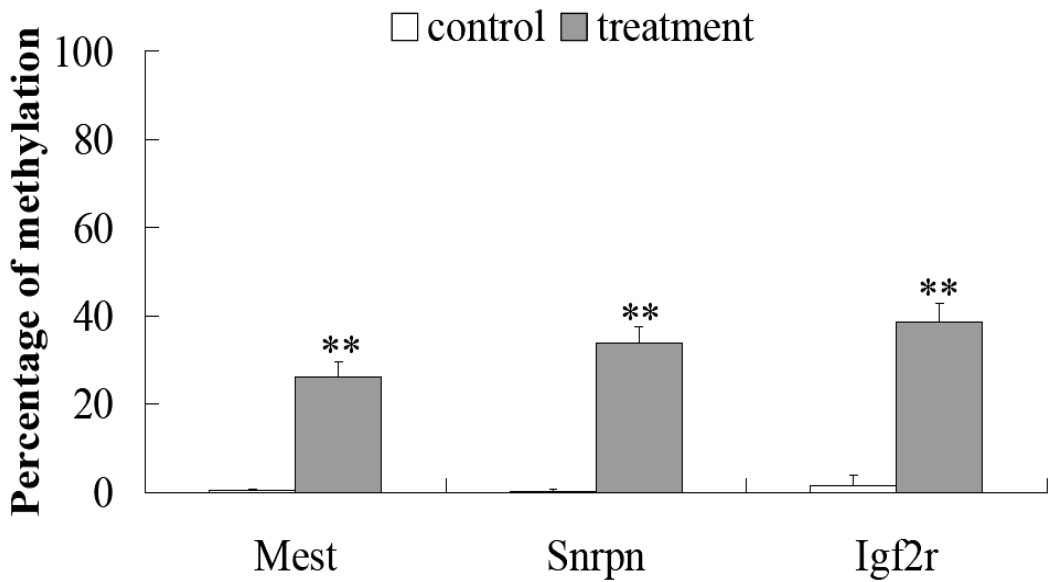

Figure 4. DNA methylation levels of Mest promoter and exon1, Snrpn DMRI and Igf2r DMR2 in the sperm cells of the control and Aroclor 1254-treated mice analyzed by BSP. Statistically significant differences to the control are presented ( “**” for $P<0.01$ ).

\section{Relative mRNA expression levels of estrogen receptor (ER) genes}

ER is regarded as a ligand-dependent transcription factor, since it recruits coactivator complexes with histone acetyltransferase or methyltransferase activities to valid downstream target genes (Hall and McDonnell, 2005). Here, we tried to determine whether Aroclor 1254, an environmental xenoestrogen, exerted its biological function via ER signaling pathways. The results demonstrated that Aroclor 1254 administration significantly up-regulated ER $\alpha$ and ER $\beta$ at the mRNA levels, in the adult male germ cells, 2-fold and 2.98-fold over control levels, respectively. ( $P<0.01$; Fig. 5).
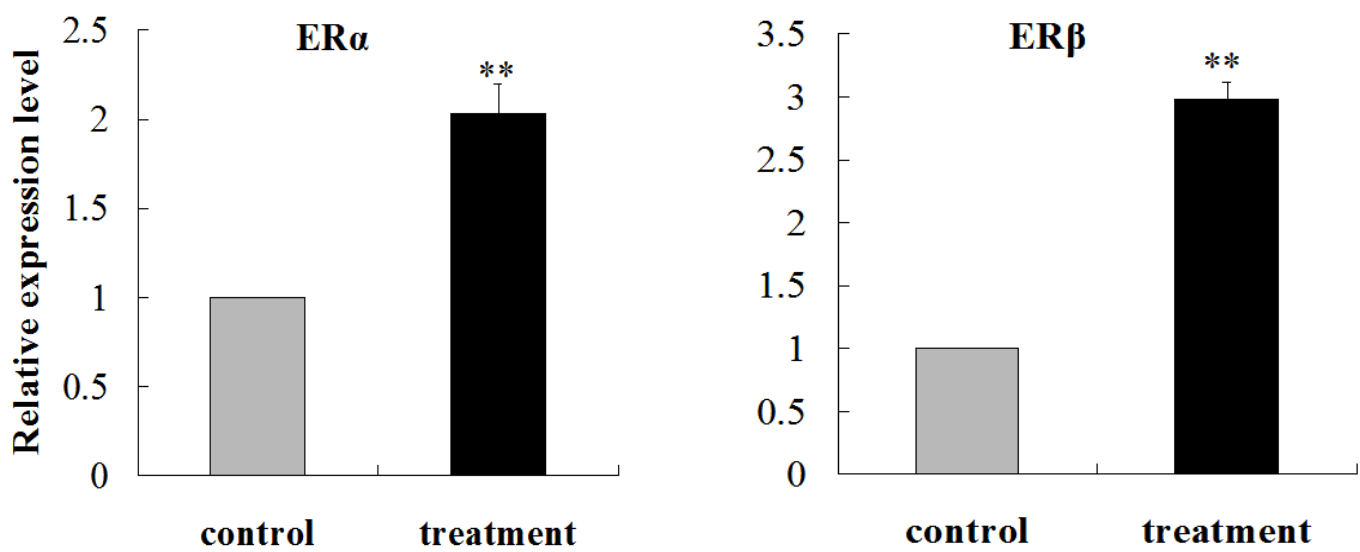

Figure 5. The relative $m R N A$ expression levels of estrogen receptors (ER $\alpha$ and $E R \beta)$ in mouse sperm cells. Aroclor 1254 administration significantly up-regulated ER $\alpha$ and ER $\beta$ at the $m R N A$

levels. The results were presented as mean $\pm S D$. “**” indicates significance of $P<0.0$ 


\section{Discussion}

A decline in sperm counts could be responsible for the currently observed decline in fertility rates. The rapidity of the changes suggested that environmental factors may play a role (Andersson et al., 2008). Among them are the endocrine-disrupting chemicals, which are substances in our environment and food that interfere with the biosynthesis, metabolism, and action of hormones. As estrogen-like and anti-androgenic endocrine-disrupting chemicals, PCBs continue to be of concern to biologists due to the reports that exposure to relatively low levels may be associated with reproductive failure in wild animals, especially in fish-eating bird (Clark et al., 1998). Preliminary results suggested that Aroclor 1254 could remarkably affect the fertilization ability of sperm, and then cause male infertility (Sikka and Wang, 2008).

DNA methylation plays a key role in regulating eukaryotic gene expression and acts as an important molecular marker underlying the parental-specific expression of genes in growth, differentiation, development and other processes (Reik and Walter, 2001). Genomic imprinting is erased in primordial germ cells in mice, and then re-established during gametogenesis (Hajkova et al., 2002). In mammals, imprinted genes show a unique expression pattern depending upon the parental origin of the derived allele (Delaval and Feil, 2004). This unique pattern of gene expression is regulated by a CpG-rich domain neighbouring the imprinted gene or gene clusters that are differentially modified by germline-specific de novo methylation mechanisms during male and female gametogenesis. The specific DNA methylation patterns in the DMRs or ICRs of imprinted genes provide a convenient way to distinguish the paternal allele from the maternal one (Bird, 1986). Patterns of DNA methylation frequently change in response to cell differentiation, disease and environmental influences. In the present study, significant decrease in methylation of two paternally (H19 and Gt12) imprinted genes and dramatic increase in methylation of three maternally (Mest, Snrpn, and Igf2r) imprinted genes in spermatozoa were observed following Aroclor 1254 treatment. A normal level of DNA methylation is required for controlling differential expression of the paternal and maternal alleles of imprinted genes ( $\mathrm{Li}$ et al., 1993). Imprinting defects in cases of disrupted spermatogenesis raised the possibility that they could be associated with infertility itself (Marques et al., 2004). The importance of genomic imprinting during spermatogenesis for male fertility has been postulated as decreased methylation of the paternal Igf2 / H19 imprinting control region 1 (ICR1) and Gt12 imprints have been found in spermatozoa of men with disturbed spermatogenesis (Kobayashi et al., 2007). Poplinski et al determined that low sperm counts were clearly associated with Igf2/H19 ICR1 hypomethylation and, even stronger, with Mest hypermethylation and idiopathic male infertility is strongly associated with imprinting defects at Igf2/H19 ICR1 and Mest, with aberrant Mest methylation being a strong indicator for sperm quality (Poplinski et al., 2010). Stouder and Paoloni-Giacobino's studies using the xenoestrogen vinclozolin (Stouder and Paoloni-Giacobino, 2010) and methoxychlor (Stouder and Paoloni-Giacobino, 2011) have also shown changes in sperm imprinted genes that can be maintained up to the F2 generation. Indeed, methylation defects in the maternally 
methylated H19 gene were observed in the sperm of oligospermic or azoospermic patients respectively (Marques et al., 2010). And these effects on the methylation pattern of the five imprinted genes tested were paralleled by a decrease in the sperm concentration. These findings indicate that the sperm DMRs provide potential epigenetic biomarkers for transgenerational disease and/or ancestral environmental exposures (Manikkam et al., 2013) and have implications for the human population that is exposed to these compounds and is experiencing significant decline in fertility and incidence of adult onset disease. Hypomethylation at the paternally imprinted loci and hypermethylation at the maternally imprinted loci indicates that Aroclor 1254 exposure dramatically interfered with the DNA methylation at the imprinted loci during spermatogenesis and may decrease the fertilizing ability or ability to produce viable embryos.

The maintenance and establishment of genomic methylation pattern in animals are catalyzed by DNA methyl transferases (Bestor, 2000). Dnmt1 is primarily responsible for maintenance methylation, and Dnmt3 family methyl transferases (Dnmt 3a and 3b) are considered responsible for de novo methylation (Bird, 2002). Dnmt 3L, a regulator of methylation contributes to acquisition of DNA methylation at paternally imprinted loci during spermatogenesis (Kylie et al., 2005). Altered methylation at the imprinted loci in spermatozoa as observed with Aroclor 1254 treatment suggests an effect of Aroclor 1254 on DNA methylation machinery during spermatogenesis. These effects may originate in methylation errors induced in the sperm by the hormonal stimulation of Aroclor 1254. The effects of Aroclor 1254 on differential DNA methylation patterns between paternally and maternally imprinted genes may be mediated by changes of expression and activity of DNA methyl transferases. However, in the present study, we cannot clarify which methyltransferase gene was responsible for dramatically altered methylation of the imprinted loci by Aroclor 1254 exposure. The mechanism of control for methylation needs further research.

As an estrogenic environmental toxin, Aroclor 1254 may exert its biological activities via estrogen receptors. There are two classical nuclear estrogen receptors, ER $\alpha$ and ER $\beta$. Since Aroclor 1254 is an estrogen-like compound, the relationship between ER and Aroclor 1254 was analyzed in our study. It revealed that Aroclor 1254 significantly increased ER $\alpha$ and ER $\beta$ expression $(P<0.01)$. ER over-expression and DNA methylation modification of imprinted genes regulate the relative gene expression (Zhang et al., 2012). Reduced DNA methylation at imprinted loci in rat spermatozoa upon tamoxifen treatment indicated a role of estrogen-associated signaling in the acquisition of paternal-specific imprints during spermatogenesis (Pathak et al., 2009). The Aroclor 1254 exposure led to a significant reduction in the methylation patterns at the differentially methylated region of paternally imprinted genes H19 and Gt12 and a significant increase in the methylation patterns of maternally inherited genes Mest, Snrpn, and Igf2r. This may be due to influences of Aroclor 1254 through the classical nuclear estrogen receptors, ER $\alpha$ and ER $\beta$. However, it is unknown whether the expression of ER is regulated by the DNA methylation. But preliminary study suggested that ER was the mediator in the process of an environmental xenoestrogen induced 
hypomethylation of imprinted genes (Chao et al., 2012). Therefore, we proposed that Aroclor 1254 influences DNA methylation of the imprinting genes via regulating ER expression.

Environmental factors affect the methylation pattern of not only imprinted genes but also a number of other target genes throughout the genome (Szyf et al., 2007). Therefore, our observations, on a selection of strategic sites, might represent only a small fraction of the genome-wide effects of PCBs Aroclor 1254.

In summary, this is the first study, to our knowledge, to provide evidence that Aroclor 1254 administration can alter the genomic DNA methylation status of imprinted genes in the sperm of adult male mouse. Our results suggest that Aroclor 1254 alters epigenetic information by inducing the paternally imprinted locus-specific DNA hypermethylation and the maternally imprinted locus-specific DNA hypomethylation in the spermatozoa. These could strengthen the premise that abnormal epigenetic reprogramming of the male germ line as a possible mechanism of compromised male fertility. In addition, because Aroclor 1254 is a SERM, changes in DNA methylation status suggest involvement of estrogen associated signaling in establishment/maintenance of the imprint. This also raises a possibility of a link between environmental estrogen and increased infertility, which could be mediated by errors in imprinting in the male germ line.

Acknowledgments. This work is supported by Jilin Environmental Protection Science Foundation (No. 20121125) and the National Natural Science Foundation of China (No. 31301850) . We appreciate the technical support of Ms. Qian Kang, College of Animal Science and Technology, Jilin Agricultural University, for bisulfite PCR.

\section{REFERENCES}

[1] Andersson, A.M., Jørgensen, N., Main, K.M., Toppari, J., Rajpert-De, M.E., Leffers, H., Juul, A., Jensen, T.K., Skakkebaek, N.E. (2008): Adverse trends in male reproductive health: we may have reached a crucial 'tipping point'. -International Journal of Andrology 31:74-80.

[2] Anway, M., Cupp, A., Uzumcu, M., Skinner, M. (2005): Epigenetic transgenerational actions of endocrine disruptors and male fertility. -Science 308:1466-1469.

[3] Bestor, T.H. (2000): The DNA methyltransferases of mammals. -Human Molecular Genetics 9:2395-2402.

[4] Bird, A. (2002): DNA methylation patterns and epigenetic memory. -Genes Development 16:6-21.

[5] Bird, A.P. (1986): CpG-rich islands and the function of DNA methylation. -Nature 321:209-213.

[6] Chang, H.S., Anway, M.A., Rekow, S.S., Skinner, M.K. (2006): Transgenerational epigenetic imprinting of the male germ line by endocrine disruptor exposure during gonadal sex determination. -Endocrinology 147: 5524-5541.

[7] Chao, H.H., Zhang, X.F., Chen, B., Pan, B., Zhang, L.J., Li, L., Sun, X.F., Shi, Q.H., Shen, W. (2012): Bisphenol A exposure modifies methylation of imprinted genes in 
mouse oocytes via the estrogen receptor signaling pathway. -Histochemistry and Cell Biology 137, 249-259

[8] Clark, K.E., Niles, L.J., Stansley, W. (1998): Environmental contaminants associated with reproductive failure in bald eagle (Haliaeetus leucocephalus) eggs in New Jersey. -Bulletin Environmental Contamination and Toxicology 61(2): 247-254.

[9] Delaval, K., Feil, R. (2004): Epigenetic regulation of mammalian genomic imprinting. -Current Opinion in Genetics and Development 14:188-195.

[10] Fielden, M.R., Halgren, R.G., Tashiro, C.H. M., Yeo, B.R., Chittim, B., Chou, K., Zacharewski, T.R. (2001): Effects of gestational and lactational exposure to Aroclor 1242 on sperm quality and in vitro fertility in early adult and middle-aged mice. -Reproductive Toxicology 15(3): 281-292.

[11] Hajkova, P., Erhardt, S., Lane, N., Haaf, T., EI-Maarri, O., Reik, W.,Walter, J., Surani, M.A. (2002): Epigenetic reprogramming in mouse primordial germ cells. -Mechanisms of Development 117(1-2):15-23.

[12] Hall, J.M., McDonnell, D.P. (2005): Co-regulators in nuclear estrogen receptor action: from concept to therapeutic targeting. -Mol. Interv. 5:343-357.

[13] Hammoud, S.S., Purwar, J., Pflueger, C., Cairns, B.R., Carrell, D.T. (2010): Alterations in sperm DNA methylation patterns at imprinted loci in two classes of infertility. -Fertility and sterility 94:1728-1733.

[14] Hitchins, M.P., Moore, G.E. (2004): Genomic imprinting in fetal growth and development. -Reprod. Med. Rev. 1:11-24.

[15] Kobayashi, H., Sato, A., Otsu, E., Hiura, H., Tomatsu, C., Utsunomiya, T., Sasaki, H., Yaegashi, N., Arima, T. (2007): Aberrant DNA methylation of imprinted loci in sperm from oligospermic patients. -Human Molecular Genetics 16: 2542-2551.

[16] Kylie, E.W., Moira, K.O., Stephen, F., Pauline, E.C., Ulla, A., Jeff, C., Dion, K.H., Hnin, A., Nawapen, P., Robert, L., Sarah, J.M., Stylianos, E.A., David. M. K., Mark, P.H., Paert, P. (2005): Meiotic and epigenetic defects in Dnmt3L-knockout mouse spermatogenesis. - PNAS 102:4068-73.

[17] Li, E., Beard, C., Jaenisch, R. (1993): Role for DNA methylation in genomic imprinting. - Nature 366: 362-365.

[18] Lucifero, D., Chaillet, J.R., Trasler, J.M. (2004): Potential significance of genomic imprinting defects for reproduction and assisted reproductive technology. - Human reproduction update 10(1): 3-18.

[19] Lucifero, D., Mertineit, C., Clarke, H.J., Bestor, T.H., Trasler, J.M. (2002): Methylation dynamics of imprinted genes in mouse germ cells. - Genomics 79:530-538.

[20] Manikkam, M., Tracey, R., Guerrero-Bosagna, C., Skinner, M.K. (2013): Plastics derived endocrine disruptors (BPA, DEHP and DBP) induce epigenetic transgenerational inheritance of obesity, reproductive disease and sperm epimutations. - PLoS ONE 8(1): e55387.

[21] Marques, C.J., Carvalho, F., Sousa, M., Barros, A. (2004): Genomic imprinting in disruptive spermatogenesis. The Lancet 363:1700-1702. 
[22] Marques, C.J., Francisco, T., Sousa, S., Carvalho, F., Barros, A., Sousa, M. (2010): Methylation defects of imprinted genes in human testicular spermatozoa. -Fertility and Sterility 94:585-594.

[23] McGrath, J., Solter, D. (1984): Completion of mouse embryogenesis requires both the maternal and paternal genomes. Cell 37:179-183.

[24] Mi, Y., Zhang, C. (2005): Toxic and hormonal effects of polychlorinated biphenyls on cultured testicular germ cells of embryonic chickens. - Toxicology Letters 155(2):297-305.

[25] Morison, I.M., Paton, C.J., Cleverley, S.D. (2001): The imprinted gene and parent-of-origin effect database. - Nucleic acids research 29:275-276.

[26] Paoloni-Giacobino, A., Chaillet, J.R. (2006): The role of DMDs in the maintenance of epigenetic states. - Cytogenetic and Genome Research 113:116-121.

[27] Pathak, S., Kedia-Mokashi, N., Saxena, M., D'Souza, R., Maitra, A., Parte, P., Gill-Sharma, M., Balasinor, N. (2009): Effect of tamoxifen treatment on global and insulin-like growth factor 2-H19 locus-specific DNA methylation in rat spermatozoa and its association with embryo loss. -Fertility and Sterility 91:2253-2263.

[28] Pflieger-Bruss, S., Schill, W. B. (2000): Effects of chlorinated hydrocarbons on sperm function in vitro. - Andrologia 32:311-315.

[29] Poplinski, A., Tüttelmann, F., Kanber, D., Horsthemke, B., Gromoll, J. (2010): Idiopathic male infertility is strongly associated with aberrant methylation of Mest and Igf2/H19 ICR1. -International Journal of Andrology 33:642-649.

[30] Reik, W., Walter, J. (2001): Genomic imprinting: parental influence on the genome. Nature Reviews Genetics. 2:21-32.

[31] Rudel, R.A., Perovich, L.J. (2009): Endocrine disrupting chemicals in indoor and outdoor air. - Atmospheric Environment 43:170-181.

[32] Safe, S.H. (1994): Polychlorinated biphenyls (PCBs): environmental impacts, biochemical and toxic responses, and implication for risk assessment. -Critical Review in Toxicology 24(2):87-149.

[33] Schug, T.T, Janesick, A., Blumberg, B., Heindel, J. J. (2011): Endocrine disrupting chemicals and disease susceptibility. -J Steroid. Biochem. Mol. Biol. 127(3-5):204-215.

[34] Sikka, S.C., Wang, R. (2008): Endocrine disruptors and estrogenic effects on male reproductive axis. -Asian Journal of Andrology. 10(1):134-145.

[35] Stouder, C., Paoloni-Giacobino, A. (2010): Transgenerational effects of the endocrine disruptor vinclozolin on the methylation pattern of imprinted genes in the mouse sperm. -Reproduction 139:373-379.

[36] Stouder, C., Paoloni-Giacobino, A. (2011): Specific transgenerational imprinting effects of the endocrine disruptor methoxychlor on male gametes. -Reproduction 141:207-216.

[37] Strogantsev, R., Ferguson-Smith, A.C. (2012): Proteins involved in establishment and maintenance of imprinted methylation marks. -Briefings in functional genomics 11(3): 227-239.

[38] Surani, M.A., Barton, S.C., Norris, M.L. (1986): Nuclear transplantation in the mouse: heritable differences between parental genomes after activation of the embryonic genome. -Cell 45:127-136. 
[39] Szyf, M., Weaver, I., Meaney, M. (2007): Maternal care, the epigenome and phenotypic differences in behavior. -Reproductive Toxicology 24:9-19.

[40] Xie, M., Zhang, C. (2004): Estrogenic and toxic effects of polychlorinated biphenyls on cultured ovarian germ cells of embryonic chickens. -Reproductive Toxicology 19(1): 79-86.

[41] Zhang, X.F., Zhang, L.J., Feng, Y.N., Chen, B., Feng, Y.M., Liang, G.J., Li, L., Shen, W. (2012): Bisphenol A exposure modifies DNA methylation of imprint genes in mouse fetal germ cells. -Molecular Biology Reports 39(9): 8621-8628.

[42] Zhou, C., Zhang, C. (2005): Protective effects of antioxidant vitamins on Aroclor 1254-induced toxicity in cultured chicken embryo hepatocytes. -Toxicology in Vitro. 19:665-673. 